\title{
The spacing effect in young children's free recall: Support for automatic-process explanations
}

\author{
THOMAS C. TOPPINO \\ Villanova University, Villanova, Pennsylvania
}

\begin{abstract}
The effect of spacing repetitions on children's free recall was investigated in two experiments. In Experiment 1, both 4-year-old children and 7-year-old children exhibited a spacing effect in free recall, and the magnitude of the effect did not change with age. In Experiment 2, free recall was examined as a function of spacing, age ( 3 years old vs. 4 years old) and presentation rate (1 vs. 2 vs. 5 sec per stimulus). A spacing effect was obtained that did not differ as a function of age or presentation rate. Of particular interest was the fact that 3-year-olds exhibited a strong spacing effect even when stimuli were presented at a very rapid 1-sec rate. The results support the hypothesis that fundamental memory mechanisms that operate relatively automatically are sufficient to produce a spacing effect in free recall.
\end{abstract}

A widely accepted generalization is that repetition improves memory, but the effectiveness of repeated exposure to information depends on the spacing between repetitions. When repetitions are massed (presented in immediate succession), their beneficial effect is often minimal. However, memory for repeated information typically improves with increases in the number of other events or items of information separating repetitions.

This spacing effect is of interest in its own right and assumes additional importance because understanding it should provide insight into the more far-reaching question of why repetition facilitates memory in the first place. Considerable research over the last two decades has indicated that the spacing effect is unusually general and robust. It has been obtained in virtually every standard memory task from free recall to recognition (Hintzman, 1974). It has been demonstrated with a wide variety of materials, both verbal (Kraft \& Jenkins, 1981) and nonverbal (Hintzman \& Rogers, 1973). It occurs with intentional memory procedures (Underwood, 1969) and with many incidental learning procedures (e.g., Glenberg \& Smith, 1981; McFarland, Rhodes, \& Frey, 1979). It seems to be relatively unaffected by variation in task parameters such as rate and modality of stimulus presentation (Melton, 1970), and attempts to eliminate or attenuate the spacing effect often have been unsuccessful (Bird, Nicholson, \& Ringer, 1978; Hintzman, Summers, Eki, \& Moore, 1975; Jensen \&

\footnotetext{
This research was supported by Grant HD21209 from the National Institute of Child Health and Human Development. I thank Pamela Blewitt, Ronald Fisher, Robert Greene, and Barry Stein for their helpful comments on an earlier draft of this paper. I also thank Kristine Krajnak, Anna Phillips, and Maria Schwendinger for assisting with the preparation of materials, data collection and/or data analyses. Correspondence should be addressed to Thomas C. Toppino, Department of Psychology, Villanova University, Villanova, PA 19085.
}

Freund, 1981; Maskarinec \& Thompson, 1976; Shaughnessy, 1976).

Most hypotheses about the mechanism(s) responsible for the spacing effect fall into one of two broad categories: encoding-variability theories and deficient-processing theories. According to encoding-variability theories (e.g., Bower, 1972; Glenberg, 1979; McFarland et al., 1979), repetition improves memory to the extent that a repeated item is encoded differently on each presentation. The spacing between repetitions is assumed to influence the degree to which repeated items are encoded differently on each occurrence, with longer spacings leading to more extensive differential encoding and better memory. According to deficient-processing theories (e.g., Jacoby, 1978; Shaughnessy, Zimmerman, \& Underwood, 1972), subjects do not fully process both occurrences of a repeated item when the spacing between repetitions is very short. Consequently, memory for the item suffers. As the spacing between repetitions increases, however, subjects become more likely to process both occurrences fully, and memory performance improves correspondingly.

One issue that cuts across theories of the spacing effect concerns whether the effect is produced by voluntary (strategic) or by involuntary (automatically activated) processes. Some encoding-variability theorists have proposed that the phenomenon is the result of sophisticated mnemonic strategies. For example, organizational strategies have been hypothesized to underlie the spacing effect in free recall (e.g., Glenberg, 1977). That is, the spacing effect is assumed to occur because, in comparison with massed repetitions, subjects are more likely to organize each occurrence of a spaced repetition into a different subjective unit, thereby increasing the likelihood of successful retrieval during free recall. Sophisticated strategic processes also have been assigned a central role in some deficient-processing theories. For example, it has been proposed that one presentation of a repeated item receives less rehearsal when the repetitions are massed than when 
they are spaced. Thus, relatively poor memory for massed repetitions is attributed to less total rehearsal (e.g., Rundus, 1971). According to another deficient-processing hypothesis, subjects allocate less attention (study time and resources) to the second occurrence of massed repetitions than they do to the second occurrence of spaced repetitions (e.g., Shaughnessy et al., 1972). In one version of this theory (Zechmeister \& Shaughnessy, 1980), subjects are assumed to adjust the allocation of study resources in accordance with metamemory judgments about how well items are learned. In any event, however, the spacing effect is assumed to occur because subjects choose to study (attend to) massed repetitions less than they do spaced repetitions.

In contrast with the strategy-based hypotheses, some researchers have noted the uncommon generality and persistence of the spacing effect and have proposed that the phenomenon reflects the operation of automatic memory processes (e.g., Jensen \& Freund, 1981) that may be so fundamental that they are hard-wired into the memory system. With respect to encoding-variability theories, for example, Glenberg (1979) proposed that automatic, encoding-variability processes are sufficient to produce the spacing effect in free recall. During study, contextual information is assumed to be encoded automatically, with more varied contextual information being encoded with spaced, as opposed to massed, repetitions. Thus, spaced repetitions are assumed to have an advantage over massed repetitions in free recall, because retrieval in free recall depends to a great degree on contextual cues. A similar hypothesis with respect to free recall was offered by Greene (1989) as part of a two-process account of the spacing effect.

Some deficient-processing theories also offer automaticprocess explanations. For example, some investigators have proposed that short spacings between repetitions interfere with ongoing consolidation processes (e.g., Landauer, 1969; Peterson, 1966). Others have proposed that, when an item is encoded, a state of habituation automatically ensues that prevents proper encoding of the same item until recovery is complete (e.g., Hintzman, 1974).

The issue of voluntary versus involuntary processes has implications for the developmental course of the spacing effect. Research on memory development indicates that very young (preschool) children do not voluntarily employ the kinds of sophisticated strategies that have been proposed to underlie the spacing effect (e.g., Appel et al., 1972; Myers \& Perlmutter, 1978; Paris, 1978). In fact, for the kinds of tasks involved in spaced-repetition research, even when the precursors of strategies have been found in preschool children, they have proved to be mnemonically ineffective (Baker-Ward, Ornstein, \& Holden, 1984; Ornstein, Baker-Ward, \& Naus, 1988). Thus, if voluntary strategic processing is necessary to produce the spacing effect, very young children should not exhibit the effect. Instead, the spacing effect should emerge with the development of children's abilities to use such strategies. However, if relatively primitive memory mechanisms that operate automatically are sufficient to produce the spacing effect, even very young children should manifest the effect. The research reported here addresses this issue in the context of free recall.

Two previous studies have examined the effect of spacing repetitions on the free-recall performance of young children (Rea \& Modigliani, 1987; Toppino \& DiGeorge, 1984). In both studies, a spacing effect was obtained with elementary-school children. However, the studies produced conflicting findings with preschool children. Rea and Modigliani obtained a spacing effect in 4-year-old preschool children, whereas Toppino and DiGeorge did not.

The source of the discrepant findings is not obvious. Comparing Toppino and DiGeorge's procedures with the procedures of Rea and Modigliani's first experiment, which was methodologically most similar, reveals numerous procedural differences. Among the most salient are the following: First, in Toppino and DiGeorge's studies, lists were composed of either 22 positions (Experiment 1), including positions for three massed- and three spacedrepetition items, or 27 positions (Experiment 2), including positions for four massed-and four spaced-repetition items. In contrast, Rea and Modigliani's lists were composed of only 16 positions, including positions for two repeated items in each of three spacing conditions (lags of 0,1 , and 3 intervening items). Second, Toppino and DiGeorge presented stimuli manually, whereas Rea and Modigliani controlled stimulus presentation and timing electronically. Third, Toppino and DiGeorge presented children with color pictures taken from picture books, and, as each picture was presented, each child supplied his or her own label, pronouncing it aloud. In contrast, Rea and Modigliani presented black-and-white line drawings in two of their four lists and typed words in the other two lists. In both picture lists and word lists, each visual stimulus was accompanied by its auditorily presented label, and children simply repeated this experimenter-supplied label aloud.

Of course, the discrepant findings might be explainable in terms of population differences or sampling error rather than in terms of methodological differences. Therefore, it was decided that, instead of attempting to systematically sort out the critical differences between the two methods, the first step should be to reexamine the effects of spacing repetitions by using the essentials of Toppino and DiGeorge's methodology. This was accomplished as part of Experiment 1, which was a factorial examination of grade level (preschool vs. second grade), spacing of repetitions (massed vs. spaced), and frequency of repetitions (two vs. three presentations).

When repeated items occurred twice, lists were very similar to those used by Toppino and DiGeorge. In addition, the procedures of both experiments reported here were very similar to those of Toppino and DiGeorge, with the exception of one potentially important improvement. Toppino and DiGeorge had presented pictures to children manually. This technique is often used in developmental 
research with young children, because it is thought that the social interaction involved helps to keep children's attention focused on the task. However, the procedure may also introduce other sources of variability. Therefore, in the present experiments, a procedure was used that was very successful in maintaining children's attention but that, at the same time, allowed stimulus presentation and timing to be controlled electronically.

Finally, frequency of repetition was examined in Experiment 1 , because it was thought that the magnitude of the spacing effect might increase as a function of this variable (Underwood, 1969). Thus, if the spacing effect is relatively weak in young children when repeated items occur twice (as suggested by Toppino and DiGeorge's failure to find an effect of spacing), the effect might be stronger and more easily detected with a greater number of presentations.

\section{EXPERIMENT 1}

\section{Method}

Subjects and Design. Subjects were 24 preschool children (mean age $=53.3$ months, age range $49-58$ months) and 24 second-grade children (mean age $=92.3$ months, age range 86-105 months) who attended nursery school and elementary school, respectively, in suburban Philadelphia. Data were collected from an additional 6 preschoolers, but these subjects were eliminated from the analyses in order to equate the number of subjects at each grade level.

Within each grade level, 12 children were randomly assigned in blocks of 2 to each of two groups that differed with respect to the order in which they studied and recalled a list containing twicepresented items and a list containing thrice-presented items (2P-3P vs. 3P-2P). The design of the experiment was a 2 (grade) $\times 2$ (order) $\times 3$ (repetition/spacing condition) $\times 2$ (type of list: $2 \mathrm{P}$ vs. 3P) mixed factorial, with the last two factors varied within-subjects. Levels of the repetition/spacing factor were: once-presented items, repeated items with massed presentations (MP), and repeated items with spaced or distributed presentations (DP).

Materials. Four list structures were generated-two 23-position structures for lists of twice-presented repeated items and two 29 position structures for lists of thrice-presented repeated items. Each structure began and ended with three slots for once-presented items serving as primacy and recency buffers, respectively. The middle portion of the list structure contained slots for two once-presented fillers and for three items representing each of the levels of the repetition/spacing variable (once-presented, MP, and DP items). The presentations of DP items were separated by lags of 3,4 , or 5 intervening items, with each lag used at least once in each list structure. Within each list structure, the mean serial positions of the final occurrences of items in the MP and DP conditions were equated with one another and with the mean serial position of the critical once-presented items.

Each subject received one list containing twice-presented items (2P list) and another list containing thrice-presented items (3P list). With respect to list structures, two combinations of $2 \mathrm{P}$ and $3 \mathrm{P}$ lists were employed, such that a $2 \mathrm{P}$ list containing the first $2 \mathrm{P}$ list structure was always paired with a $3 \mathrm{P}$ list containing the first $3 \mathrm{P}$ list structure, and a $2 \mathrm{P}$ list containing the second $2 \mathrm{P}$ list structure was always paired with a 3P list containing the second 3P list structure. Half of the subjects in each group received one of these pairings; the remaining half of the subjects in each group received the other pairing.

Stimuli presented in the lists were colored pictures of common objects taken from children's picture collections. Two sets of 17 pictures were selected so that each picture would be familiar to young children but would bear no strong or obvious semantic relationships to other pictures in the same set. Items within each set of 17 pictures were randomly assigned to serve specific functions (e.g. critical items, buffers, fillers). Then, pictures in one set of items were assigned to positions in one of the list structures of twicepresented repetitions and to positions in one of the list structures of thrice-presented repetitions. Pictures in the other set of 17 items were assigned to positions in the remaining two list structures. For each of the four original lists constructed in this fashion, two new lists were generated in which the critical items were reassigned to repetition/spacing conditions within the same list structure according to a Latin-square principle. This allowed the assignment of lists to children to be done in such a way that, both between and within order groups, the same items served equally often in each repetition/spacing condition.

To prepare lists for presentation, the picture stimuli were prepared as slides, and electronically timed slide sequences were videotaped with a Panasonic WV3260 color video camera.

Procedure. The children participated individually in the experiment, which was presented as a "memory game." They sat before a 9-in. color-television monitor as lists were presented by videotape.

After the children studied and recalled a short practice list, the first experimental list was presented. One picture was presented every 5 sec with a .8 -sec interstimulus interval, and the children labeled each picture as it appeared. Following list presentation, the children were allowed $2 \mathrm{~min}$ for oral free recall. They were credited with correctly recalling an item if they provided, during the recall test, either the item's conventional label or an idiosyncratic label that they had given previously during list presentation. When the recall period was over, there was a 2 -min rest period during which the children worked on a simple puzzle. Then, the procedure was repeated with the second experimental list.

\section{Results and Discussion}

Table 1 presents the mean percentage of correct free recall as a function of grade level, type of list, and repetition/spacing condition. The repetition/spacing factor is actually a combination of two logically separable variables: repetition (once-presented vs. repeated) and the spacing between repetitions (MP vs. DP). Therefore, the effects of these two variables were examined in separate analyses.

Table 1

Mean Percentage of Correct Recall as a Function of Grade Level, Type of List (Containing 2P Items vs. Containing 3P Items), and Repetition/Spacing Condition in Experiment 1

\begin{tabular}{lccc}
\hline & \multicolumn{3}{c}{ Repetition/Spacing } \\
\cline { 2 - 4 } & 1P & MP & DP \\
\hline 2P lists & 23.5 & 29.1 & \\
3P lists & 26.3 & 33.2 & 46.0 \\
Mean & 24.9 & 31.2 & 40.9 \\
& Grade Two & & \\
2P lists & 27.6 & 41.6 & 54.2 \\
3P lists & 24.9 & 61.2 & 65.3 \\
Mean & 26.3 & 51.4 & 59.8 \\
\hline
\end{tabular}

Note-1P $=$ once-presented items, MP $=$ massed presentations, DP $=$ distributed presentations, $2 \mathrm{P}$ lists $=$ lists containing twice-presented items, 3P lists $=$ lists containing thrice-presented items. 
The first analysis assessed the effect of repetition per se on the percentage of items correctly recalled, with the use of a $2 \times 2 \times 2 \times 2$ (grade $\times$ order $\times$ repetition $x$ type of list) ANOVA with repeated measures on the last two factors. Neither the main effect of order nor any interactions involving this variable were significant [all $\left.F_{s}(1,44) \leq 1.06\right]$. The repetition variable compared the mean percentage of critical once-presented items recalled with the mean percentage of repeated items recalled, including both MP and DP items. The effect of this factor was significant $\left[F(1,44)=39.69, M S_{\mathrm{e}}=495.72\right.$, $p<.001$ ], indicating that recall was better for repeated items than it was for once-presented items. Recall was better in lists involving thrice-presented repetitions than it was in lists involving twice-presented repetitions $\left[F(1,44)=5.68, M S_{\mathrm{e}}=265.77, p<.025\right]$. Although this difference was primarily due to recall of repeated as opposed to once-presented items in these lists, the repetition $\times$ type-of-list interaction did not reach conventional levels of significance $\left[F(1,44)=2.77, M S_{c}=528.47\right.$, $p=.10]$. Finally, recall was better for second graders than it was for preschoolers $\left[F(1,44)=7.46, M S_{\mathrm{e}}=\right.$ $704.77, p<.01]$, and there was a grade $\times$ repetition interaction $\left[F(1,44)=8.00, M S_{\mathrm{e}}=495.72, p<.01\right]$, indicating that second graders benefited more from repetition than did preschoolers. No other interactions were significant [all $F \mathrm{~s}(1,44) \leq 1.10]$.

The effect of spacing repetitions was examined in a second $2 \times 2 \times 2 \times 2$ (grade $\times$ order $\times$ spacing $\times$ type of list) ANOVA with repeated measures on the last two factors. Again, neither the main effect of order nor any of the interactions involving order approached significance [all $F$ s $(1,44) \leq 1.09$ ]. A main effect of list type (which is equivalent to frequency of repetition in this case) indicated that recall was better for $3 \mathrm{P}$ items than it was for $2 \mathrm{P}$ items $\left[F(1,44)=7.90, M S_{\mathrm{e}}=753.06, p<.01\right]$. However, list type was not systematically related to any other variable, as reflected in the fact that no interactions involving this factor even approached significance ( $F \mathrm{~s} \leq$ 1.12). Second graders recalled better than preschoolers $\left[F(1,44)=18.48, M S_{\mathrm{e}}=993.21, p<.001\right]$, but the most important finding was a significant spacing effect $\left[F(1,44)=5.01, M S_{e}=788.94, p<.05\right]$, with DP items being recalled better than MP items. Neither grade level nor spacing interacted significantly with any other variable (all $F \mathrm{~S} \leq 1.12$ ). Thus, the results of this experiment indicate that young children exhibit a spacing effect that undergoes no significant change between the ages of 4 and 7 years old.

\section{EXPERIMENT 2}

Experiment 1 included conditions that were methodologically very similar to those of Toppino and DiGeorge (1984), whose results were consistent with the hypothesis that the spacing effect is produced by strategies that emerge with development. However, the results of Experiment 1, like those of Rea and Modigliani (1987), did not support this hypothesis. Preschoolers exhibited a spacing effect, and the effect did not change with development between the preschool and early elementary-school years.

Although the preschoolers in all of the above experiments were approximately the same chronological age (i.e., 4 years old), one cannot rule out the possibility that the subjects in Experiment 1 and in Rea and Modigliani's study were cognitively more advanced in their development than were the children sampled by Toppino and DiGeorge. That is, the former studies may have failed to detect the developmental change predicted by the strategy hypothesis because their 4-year-old subjects may have been so advanced that they had already undergone the predicted developmental changes in cognitive functioning. This possibility would be greatly reduced, however, if even younger children could be shown to exhibit a spacing effect in free recall. Therefore, in Experiment 2, the age of preschoolers was varied to include both 3- and 4-year-old children.

We further examined the issue of strategic versus automatic processes by varying the presentation rate $(1,2$, or $5 \mathrm{sec}$ per picture). Voluntary processes require time to execute. Some investigators (e.g., Stoff \& Eagle, 1971; Wilkinson \& Koestler, 1983) have suggested that a 1-sec presentation rate may be too fast for adults to implement a voluntary strategy. This seems especially likely in the case of children as young as 3 years old. Thus, if the spacing effect in preschool children is, by any chance, the result of some undetected voluntary strategy, the spacing effect should be evident when presentation rates are relatively slow (e.g., $5 \mathrm{sec}$ ) but should be eliminated with a 1-sec presentation rate. In contrast, if fundamental, automatic, memory processes are sufficient to produce the spacing effect in free recall, a spacing effect should be evident even when to-be-remembered stimuli are presented at a 1-sec rate.

\section{Method}

Materials and Procedures. Three 22-position list structures were generated. These began and ended with slots for three primacy buffers and three recency buffers, respectively. The middle region of the structures contained slots for 1 once-presented filler item and for 3 items representing each of the levels of the repetition/spacing variable (once-presented, MP, and DP items). All repeated items were presented twice, and presentations of DP items were separated by a lag of 3 intervening items. The serial position of critical items within the list structure was controlled, as in Experiment 1.

Stimuli consisted of either 48 color pictures of common objects taken from children's picture collections or 48 black-ink drawings on a white background taken from a set of pictures published by Snodgrass and Vanderwart (1980). Each black-and-white picture corresponded to one of the color pictures in that it depicted the same type of object having the same label (e.g., another hammer, chair, dog, etc.). A given list contained only one type of stimulus, and two sets of lists were constructed that were identical, except for the type of stimuli that were employed in each.

The sets of $\mathbf{4 8}$ pictures comprised three subsets of 16 such that the depicted objects had no strong or obvious semantic relationships to other members of the same subset. Each subset of 16 items was assigned to a different one of the three list structures. Follow- 
ing the procedures outlined in Experiment 1, stimuli within each subset of items were assigned functions (e.g., MP items) and then were assigned to slots in the designated list structure. By using a Latin-square principle, we generated two more lists with each item-subset/list-structure combination such that, across the three lists involving a given list structure, the same stimulus items served equally often in each of the three repetition/spacing conditions. By this procedure, we generated nine lists of color pictures and a corresponding nine lists of black-and-white pictures.

Materials were prepared for presentation by videotaping a series of electronically timed slides, as in Experiment 1 . The presentation rates of 1,2 , and $5 \mathrm{sec}$ refer to the interval from the onset of one stimulus to the onset of the next. However, there was a .8sec blank interval between the offset of one stimulus and the onset of its successor

The subjects received three successive lists with one list presented at each of the three presentation rates. Therefore, for each type of stimulus, we used a complex counterbalancing scheme to generate and record 27 sequences of three lists so that each sequence included one list of each of the three different subsets of 16 pictures and one list presented at each of the three different presentation rates (1, 2, or 5 sec per item). Across all 27 sequences, each of the nine basic lists (see above) occurred equally often at each of the three presentation rates and was presented at each of these presentation rates equally often as the first, second, and third list in a sequence.

Procedures were the same as in Experiment 1, except that three, rather than two, successive lists were presented and recalled.

Subjects and Design. Subjects were 543 -year-old children (mean age $=42.7$ months, age range $=36-47$ months) and 544 -yearold children (mean age $=53.9$ months, age range $=48-59$ months) who attended nursery school in suburban Philadelphia. Within each age group, each of the 27 list sequences of color stimuli and each of the 27 list sequences of black-and-white stimuli were assigned randomly to one child. The overall design can be conceptualized as a 2 (age) $\times 2$ (type of stimulus) $\times 3$ (presentation-rate order) $\times 3$ (presentation rate) $\times 3$ (repetition $/$ spacing) mixed factorial, with the last two factors varied within subjects. The presentationrate-order variable refers to the presentation rate of successive lists in the sequence of three lists presented to a subject $(1,2,5$ vs. 5 , $1,2$ vs. $2,5,1)$. Neither this variable nor the type-of-stimulus variable was of theoretical interest. The former was included for purposes of control; the latter was included to increase generality.

\section{Results and Discussion}

Table 2 presents the mean percentage of correct free recall as a function of age, presentation rate, and repetition/spacing condition. As in the previous experiment, the results were analyzed by two ANOVAs. The first examined the effect of repetition per se in a $2 \times 2 \times 3 \times$ $3 \times 2$ (age $\times$ stimulus type $\times$ presentation-rate order $X$ presentation rate $X$ repetition) mixed ANOVA with repeated measures on the last two factors. The second ANOVA, which examined the effect of the spacing between repeated items, was identical to the first except that the repetition factor (once-presented vs. twice-presented items) was replaced by spacing (MP vs. DP items).

The first ANOVA indicated that recall was better for twice-presented items than it was for once-presented items $\left[F(1,96)=23.73, M S_{\mathrm{e}}=492.61, p<.001\right]$, and this effect of repetition did not interact significantly with any other variable. Other effects paralleled those obtained with the second ANOVA, to which we now turn.

As expected, the percentage of repeated items recalled was greater for 4-year-olds than it was for 3-year-olds
Table 2

Mean Percentage of Correct Recall as a Function of Age, Presentation Rate, and Repetition/Spacing Condition in Experiment 2

\begin{tabular}{llll}
\hline & \multicolumn{3}{c}{ Repetition/Spacing } \\
\cline { 2 - 4 } & 1P & MP & DP \\
\hline 3-Year-Olds & & \\
1-sec rate & 16.1 & 17.3 & 29.6 \\
2-sec rate & 21.0 & 22.2 & 25.9 \\
5-sec rate & 20.4 & 19.1 & 28.4 \\
Mean & 19.2 & 19.5 & 28.0 \\
& $4-$ Year-Olds & & \\
1-sec rate & 22.2 & 22.8 & 28.8 \\
2-sec rate & 16.1 & 29.6 & 38.9 \\
5-sec rate & 19.8 & 26.5 & 35.2 \\
Mean & 19.4 & 26.3 & 34.3 \\
\hline
\end{tabular}

Note-1P $=$ once-presented items, $M P=$ massed presentations, DP $=$ distributed presentations

$\left[F(1,96)=6.87, M S_{\mathrm{e}}=990.21, p=.01\right]$. Also, the children's performance did not improve systematically with presentation rate. The main effect of presentation rate was not reliable $\left[F(2,192)=2.08, M S_{e}=562.63, p>.10\right]$, with the mean percentage of recall equal to $24.5,29.2$, and 27.3 for the 1-, 2-, and 5-sec presentation rates, respectively. This finding is consistent with the assumption that, at this age, children do not employ effective mnemonic strategies.

However, two interactions must be mentioned, even though they do not change the interpretation of the presentation-rate data. First, there was a significant presentation rate $\times$ presentation-rate order interaction $\left[F(4,192)=5.17, M S_{\mathrm{e}}=562.63, p<.001\right]$, which simply reflected the fact that recall performance declined across the three successive lists given to each child. Thus, the relative performance among the three presentation rates depended on the order in which lists involving the different presentation rates were presented. Second, there was a marginally reliable interaction between presentation rate and type of stimulus $\left[F(2,192)=2.96, M S_{\mathrm{e}}=\right.$ $562.63, p=.054]$. The mean percentages of recall for the $1-, 2-$, and 5-sec presentation rates were, respectively, $27.5,26.5$, and 27.5 for color stimuli, and 21.6, 31.8, and 27.2 for black-and-white stimuli. Thus, the marginal interaction seems to stem from relatively poor performance when children encountered black-and-white stimuli at a 1 -sec presentation rate. However, the effect of presentation rate with black-and-white stimuli was not reliable in a probe of simple main effects $\left[F(2,192)=2.50, M S_{c}=\right.$ $562.63, p>.05]$.

There are other reasons, as well, for believing that the interaction was spurious. Although no higher order interaction approached significance, poor recall with blackand-white stimuli presented at a 1 -sec rate was traceable to the fact that, in this condition, 4-year-olds performed unusually poorly on spaced repetitions. For no discernible reason, 4-year-olds performed more poorly than did 3 -year-olds in this one condition, whereas the opposite pattern was obtained in every other one of the 12 condi- 
tions generated from two types of stimuli, three presentation rates, and two levels of spacing. Finally, if the increase in performance from 1 to $2 \mathrm{sec}$ per picture indicated that children used the extra time to engage in additional mnemonic processing, one should expect a further increase in performance at even slower rates. One should also expect the strategy to be employed with color, as well as black-and-white, stimuli. However, neither of these expectations was supported by the data. ${ }^{1}$

Turning to the most important findings revealed by the second ANOVA, there was a significant main effect of spacing $\left[F(1,96)=12.67, M S_{\mathrm{e}}=802.50, p<.001\right]$ such that children recalled DP items better than they did MP items. Moreover, the spacing between repetitions did not interact significantly with age $[F(1,96)<1.00]$, presentation rate $[F(2,192)<1.00]$, or any other variable or combination of variables (all $F \mathrm{~s} \leq 1.37$ ).

Of particular interest was whether or not the youngest children (3-year-olds) would exhibit a spacing effect with a 1-sec presentation rate. It was thought that this rate was fast enough to preclude virtually any undetected strategic processing in which these children might engage. A separate analysis of 3-year-olds' performance with the 1sec presentation rate showed that the spacing effect in these children was significant $\left[F(1,53)=7.76, M S_{\mathrm{e}}=\right.$ 530.34, $p<.01$ ].

\section{GENERAL DISCUSSION}

Preschool children, who are unsophisticated with respect to mnemonic strategies, exhibited a spacing effect in both of the experiments reported here. In Experiment 1, 4-year-olds manifested a spacing effect that did not differ from the spacing effect produced by second graders. In Experiment 2, 3-year-olds, as well as 4-yearolds, were found to exhibit a spacing effect.

These findings are consistent with previous findings reported by Rea and Modigliani (1987), but they are in conflict with the findings of Toppino and DiGeorge (1984), who obtained no spacing effect in preschool children. The cause of the discrepant results is far from obvious. The primary methodological difference between the current experiments and those of Toppino and DiGeorge is that stimulus presentation was more precisely controlled in the present experiments. The fact that 3-yearolds produced a spacing effect in Experiment 2 makes it extremely unlikely that Toppino and DiGeorge's results are attributable to a sample of cognitively less advanced 4-year-olds. Although one cannot rule out the possibility that Toppino and DiGeorge's results are systematically replicable under some highly specific and subtle set of circumstances, the present findings, in conjunction with those reported by Rea and Modigliani, clearly indicate that preschool children generally exhibit a spacing effect in free recall under a wide variety of experimental conditions.

The fact that preschool children manifest a spacing effect in free recall is difficult to reconcile with encoding- variability theories based on the use of organizational strategies (e.g., Glenberg, 1977) and with deficientprocessing theories emphasizing the role of rehearsal (e.g., Rundus, 1971). Preschoolers do not spontaneously engage in organizational strategies (e.g., Bjorklund \& Jacobs, 1985; Moely, 1977), nor do they evidence verbal rehearsal or elaboration (Wellman, 1988) in tasks such as those used to study spaced-repetition effects.

In addition, the performance of preschoolers creates at least three problems for deficient-processing theories in which the spacing effect is attributed to voluntary allocation of attention (study time and resources) to the second occurrence of repeated items (e.g., Hintzman, 1974; Shaughnessy et al., 1972; Zechmeister \& Shaughnessy, 1980). First, the theories are vague. When subjects allocate attention to an item, some form of postperceptual mnemonic processing seems to be assumed, but its nature is unclear. To account for findings obtained from preschoolers, one must hypothesize an elementary form of mnemonic processing to which subjects can voluntarily allocate attentional resources but which differs from what we usually mean by rehearsal and/or elaboration. Second, these theories assume that, as each item in a list is presented, subjects evaluate the item on some basis and modify their processing of the item accordingly. However, this kind of flexible, self-regulated processing is not characteristic of very young children. Third, one specific hypothesis is that the amount of study time and resources allocated to an item depends upon a metamemory judgment of how well the item is learned (Zechmeister \& Shaughnessy, 1980). However, there is reason to believe that the strategy of studying unlearned items more than learned items may not develop until children are considerably older. For example, in the context of simple multitrial tasks, there is evidence that even 6- and 7-year-olds fail to differentially allocate study time as a function of whether or not an item was recalled on an immediately preceding test (Bisanz, Vesonder, \& Voss, 1978; Masur, McIntyre, \& Flavell, 1973).

It is possible that some voluntary, but as yet unidentified, strategy is necessary to produce the spacing effect. However, this possibility seems remote in light of the results of Experiment 2, which varied presentation rate and extended previous work with 4-year-olds to younger, developmentally less advanced 3-year-olds. Given that both initial encoding and subsequent conscious-decision processes take time and that they tend to take longer in younger children (Siegler, 1986), very fast presentation rates should inhibit strategic processes and their effects in children, whereas the effects of voluntary processes should be most apparent when relatively slow presentation rates are used. Results indicated that even 3-yearold children exhibited a strong spacing effect in free recall with a very rapid 1-sec presentation rate. Furthermore, there was no tendency for the spacing effect to become more pronounced with slower rates. These findings are most consistent with the hypothesis that fundamentaleven primitive-memory mechanisms that operate auto- 
matically and are available from a very young age are sufficient to produce a spacing effect in free recall.

The results of the present experiments are consistent with several theories that have attributed spacing effects to automatic processes. Among encoding-variability theories, those of both Glenberg (1979) and Greene (1989) suggest that, as the spacing between repetitions increases, more varied contextual information automatically is encoded with the repeated item. Thus, free recall is facilitated because more contextual cues can serve as effective retrieval cues. ${ }^{2}$ Unfortunately, although these theories are compatible with the findings reported here, the fundamental assumption underlying encoding-variability theories has not always been supported. According to this assumption, increasing the number of retrieval routes through varied encoding increases the probability of successful retrieval, thus improving memory performance. Although this assumption has received support under limited circumstances (e.g., McDaniel \& Masson, 1985), other attempts to provide direct support for this assumption frequently have failed (e.g., Maki \& Hasher, 1975; Postman \& Knecht, 1983).

The present findings are also consistent with several deficient-processing theories, including consolidation theory (e.g., Landauer, 1969; Peterson, 1966) and habituation theory (Hintzman, 1974). According to the former theory, consolidation of one presentation interferes with consolidation of the other presentation when repetitions occur too closely to one another. The result is a weakened memory trace brought about by less total consolidation (Hintzman, 1974). According to habituation theory, encoding the first presentation habituates some encoding process so that the second presentation cannot be encoded properly until enough time has elapsed for recovery to occur (Hintzman, 1974). Although these theories are consistent with the findings reported here, which seem to limit the viability of voluntary-strategy explanations of the spacing effect, they are not without problems. As Rea and Modigliani (1987) noted, some of their hypothesized mechanisms (e.g., the time course of consolidation or recovery from habituation) are not well specified, making them difficult to test. Perhaps for this reason, there is little evidence actually supporting these theories (e.g., Hintzman, Summers, \& Block, 1975).

A final class of deficient-processing theories that will be considered emphasizes the role of retrieval operations (e.g., Cuddy \& Jacoby, 1982; Jacoby, 1978). The second presentation of an item is assumed to initiate retrieval of the first presentation (study-phase retrieval). If repetitions are massed, retrieval of the first presentation is so trivial that little processing is involved. As the spacing between repetitions increases, successful retrieval requires increased processing, which results in improved memory on a later test.

This version of deficient-processing theory does not specify whether the assumed processes are voluntary or involuntary in nature. However, such a theory would be consistent with our findings if one assumed that studyphase retrieval is a basic and automatic component of processing repeated information. This assumption seems reasonable when one considers that retrieval is clearly one of the most fundamental processes of the memory system and that it can be triggered automatically by presenting appropriate cues.

A deficient-processing mechanism based on retrieval processes is easily reconciled with the complementary view that successful study-phase-retrieval operations contribute significantly to the beneficial effect of repetition (e.g., Thios \& D'Agostino, 1976; Whitten \& Bjork, 1977). Also, it is compatible with findings indicating that spaced-repetition effects may occur only for items that are recognized as repetitions (e.g., Madigan, 1969) and that, when a single study opportunity is followed by two tests, performance on the final test improves as a function of the spacing between studying and the initial test (e.g., Modigliani, 1976; Whitten \& Bjork, 1977).

In summary, the present findings extend the generality of the spacing effect and place constraints on the form that a satisfactory theory of the spacing effect can take. The results suggest that very fundamental memory mechanisms that operate largely automatically are sufficient to produce the spacing effect in free recall. However, several caveats are appropriate in closing. First, although voluntary strategic processes do not seem to be necessary to produce the spacing effect in free recall, it remains possible that the effect may be augmented or otherwise influenced by voluntary strategies after they are acquired. Second, some investigators have suggested that two spaced-repetition effects should be distinguished: a "spacing effect" and a "lag effect" (e.g., D'Agostino \& DeRemer, 1972; Hintzman, 1974). Much of the spacedrepetition literature has focused on the spacing effect, which includes MP versus DP contrasts, as well as the effects of short spacings between repetitions, whereas the lag effect includes the effect of relatively long spacings between repetitions. The results and conclusions of the present research clearly apply to the spacing effect. However, to the extent that these two effects can be functionally distinguished, the present conclusions may not extend to the lag effect. Third, and finally, much of the research on the spacing effect has involved free recall. However, there is evidence that somewhat different processes may underlie the spacing effect in free recall and in cued-memory tasks such as recognition (Glenberg \& Smith, 1981; Greene, 1989). Thus, it remains possible that voluntary processes are necessary to produce the spacing effect in cued-memory tasks, as Greene (1989) has recently suggested.

\section{REFERENCES}

Appel, L. F., CoOper, R. G., MCCArrell, N., Sims-Knight, J., YusSEN, S. R., Flavell, J. H. (1972). The development of the distinction between perceiving and memorizing. Child Development, $\mathbf{4 3}$, 1365-1381

Baker-W ARd, L., Ornstein, P. A., Holden, D. J. (1984). The expression of memorization in early childhood. Joumal of Experimental Child Psychology, 37, 555-575.

Bird, C. P., Nicholson, A. J., Ringer, S. (1978). Resistance of 
the spacing effect to variations in encoding. American Journal of Psychology, 91, 713-721.

Bisanz, G. L., Vesonder, G. T., \& Voss, J. F. (1978). Knowledge of one's own responding and the relation of such knowledge to learning. Journal of Experimental Child Psychology, 25, 116-128.

BJoRKLUND, D. F., \& JACOBS, J. W., III. (1985). Associative and categorical processes in children's memory: The role of automaticity in the development of organization in free recall. Joumal of Experimental Child Psychology, 39, 599-617.

Bower, G. H. (1972). Stimulus-sampling theory of encoding variability. In A. W. Melton \& E. Martin (Eds.), Coding processes in human memory (pp. 85-123). Washington: Winston.

CUDDY, L. J., \& JACOBY, L. L. (1982). When forgetting helps memory: An analysis of repetition effects. Journal of Verbal Learning \& Verbal Behavior, 21, 451-467.

D'Agostino, P. R., \& DeRemer, P. (1972). Item repetition in free and cued recall. Journal of Verbal Learning \& Verbal Behavior, 11, 54-58.

GLENBERG, A. M. (1977). Influences of retrieval processes on the spacing effect of free recall. Joumal of Experimental Psychology: Human Learning \& Memory, 3, 282-294.

GLENBERG, A. M. (1979). Component-levels theory of the effects of spacing of repetitions on recall and recognition. Memory \& Cognition, 7, 95-112.

GlenberG, A. M., \& SMith, S. M. (1981). Spacing repetitions and solving problems are not the same. Joumal of Verbal Learning \& Verbal Behavior, 20, 110-119.

GREENE, R. L. (1989). Spacing effects in memory: Evidence for a twoprocess account. Journal of Experimental Psychology: Learning, Memory, \& Cognition, 15, 371-377.

Hintzman, D. L. (1974). Theoretical implications of the spacing effect. In R. L. Solso (Ed.), Theories in cognitive psychology: The Loyola Symposium (pp. 77-99). Hillsdale, NJ: Erlbaum.

Hintzman, D. L., \& Rogers, M. K. (1973). Spacing effects in picture memory. Memory \& Cognition, 1, 430-434.

Hintzman, D. L., Summers, J. J., \& Block, R. A. (1975). What causes the spacing effect? Some effects of repetition, duration, and spacing on memory for pictures. Memory \& Cognition, 3, 287-294.

Hintzman, D. L., Summers, J. J., EkI, N. T., \& Moore, M. D. (1975). Voluntary attention and the spacing effect. Memory \& Cognition, 3, 576-580.

JACOBY, L. L. (1978). On interpreting the effects of repetition: Solving a problem versus remembering a solution. Joumal of Verbal Leaming \& Verbal Behavior, 17, 649-667.

JENSEN, T. D., \& FREUNd, J. S. (1981). Persistence of the spacing effect in incidental free recall: The effect of external list comparisons and intertask correlations. Bulletin of the Psychonomic Society, 18, 183-186.

Kraft, R. N., \& Jenkins, J. J. (1981). The lag effect with aurally presented passages. Bulletin of the Psychonomic Society, 17, 132-134.

Landauer, T. K. (1969). Reinforcement as consolidation. Psychological Review, 76, 82-96.

Madigan, S. A. (1969). Interserial repetition and coding processes in free recall. Journal of Verbal Leaming \& Verbal Behavior, 8, 828-835.

MAKI, R. H., \& HASHER, L. (1975). Encoding variability: A role in immediate and long-term memory. American Journal of Psychology, 88, 217-231.

Maskarinec, A. S., \& Thompson, C. P. (1976). The within-list distributed practice effect: Tests of the varied context and varied encoding hypotheses. Memory \& Cognition, 4, 741-746.

Masur, E. F., McIntyre, C. W., \& Flavell, J. H. (1973). Developmental changes in apportionment of study time among items in a multitrial free recall task. Joumal of Experimental Child Psychology, 15, 237-246.

McDaniel, M. A., \& Masson, M. E. J. (1985). Altering memory representations through retrieval. Journal of Experimental Psychology: Learning, Memory, \& Cognition, 11, 371-385.

McFarland, C. E., Rhodes, D. D., \& Frey, T. J. (1979). Semanticfeature variability and the spacing effect. Journal of Verbal Learning \& Verbal Behavior, 18, 163-172.
Melton, A. W. (1970). The situation with respect to the spacing of repetitions and memory. Journal of Verbal Learning \& Verbal Behavior, 9, 596-606.

ModigliaNI, V. (1976). Effects on a later recall by delaying initial recall. Journal of Experimental Psychology: Human Learning \& Memory, 2, 609-622.

MOELY, B. E. (1977). Organizational factors in the development of memory. In R. V. Kail, Jr., \& J. W. Hagen (Eds.), Perspectives on the development of memory and cognition (pp. 203-236). Hillsdale, NJ: Erlbaum.

Myers, N. A., Perlmutter, M. (1978). Memory in the years from two to five. In P. A. Ornstein (Ed.), Memory development in children (pp. 191-218). Hillsdale, NJ: Erlbaum.

Ornstein, P. A., Baker-WARD, L., \& Naus, M. J. (1988). The development of mnemonic skill. In F. E. Weinert \& M. Perlmutter (Eds.), Memory development: Universal changes and individual differences (pp. 31-50). Hillsdale, NJ: Erlbaum.

PARIS, S. G. (1978). The development of inference and transformation as memory operations. In P. A. Ornstein (Ed.), Memory development in children (pp. 129-156). Hillsdale, NJ: Erlbaum.

Peterson, L. R. (1966). Short-term verbal memory and learning. Psychological Review, 73, 193-207.

Postman, L., KNECHT, K. (1983). Encoding variability and retention. Journal of Verbal Leaming \& Verbal Behavior, 22, 133-152.

Rea, C. P., \& Modigliani, V. (1987). The spacing effect in 4- to 9year-old children. Memory \& Cognition, 15, 436-443.

RuNDUS, D. (1971). Analysis of rehearsal processes in free recall. Journal of Experimental Psychology, 89, 63-77.

Shaughnessy, J. J. (1976). Persistence of the spacing effect in free recall under varying incidental learning conditions. Memory \& Cognition, 4, 369-377.

Shaughnessy, J. J., Zimmerman, J., \& Underwood, B. J. (1972). Further evidence on the MP-DP effect in free-recall learning. Journal of Verbal Learning \& Verbal Behavior, 11, 1-12.

SIEGLER, R. S. (1986). Children's thinking. Englewood Cliffs, NJ: Prentice-Hall.

Snodgrass, J., VANDERWARD, M. (1980). A standardized set of 260 pictures: Norms for name agreement, image agreement, familiarity and visual complexity. Journal of Experimental Psychology: Human Learning \& Memory, 6, 174-215.

StofF, D. M. \& EAGLE, M. N. (1971). The relationship among reported strategies, presentation rate, and verbal ability and their effects on free-recall learning. Joumal of Experimental Psychology, 87, 423-428.

Thios, S. J., D'Agostino, P. R. (1976). Effects of repetition as a function of study-phase retrieval. Journal of Verbal Learning \& Verbal Behavior, 15, 529-536.

Toppino, T. C., DiGeorge, W. (1984). The spacing effect in free recall emerges with development. Memory \& Cognition, 12, 118-122.

UNDERWOOD, B. J. (1969). Some correlates of item repetition in freerecall learning. Joumal of Verbal Learning \& Verbal Behavior, 8 , 83-94.

Wellman, H. M. (1988). The early development of memory strategies. In F. E. Weinert \& M. Perlmutter (Eds.), Memory development: Universal changes and individual differences (pp. 3-29). Hillsdale, NJ: Erlbaum.

WhitTEN, W. B., II, \& BJoRK, R. A. (1977). Learning from tests: Effects of spacing. Journal of Verbal Learning \& Verbal Behavior, 16, 465-478.

Wilkinson, A. C., \& Koestler, R. (1983). Repeated recall: A new model and tests of its generality from childhood to old age. Journal of Experimental Psychology: General, 112, 423-451.

Zechmeister, E. B., Shaughnessy, J. J. (1980). When you know that you know and when you think that you know but you don't. Bulletin of the Psychonomic Society, 15, 41-44.

\section{NOTES}

1. The lack of any rate effect, although anticipated in preschoolers, left open the possibility that the conditions of this experiment were in- 
sufficient to produce a rate effect in any subjects-even those known to employ sophisticated strategies in apparently similar circumstances. Therefore, as a manipulation check, the same materials and procedures were employed with 54 college students. These subjects' recall improved steadily as presentation rate became slower, as would be expected if they were using sophisticated mnemonic strategies $[F(2,106)=3.30$, $\left.M S_{\mathrm{e}}=806.79, p<.05\right]$. The mean percentage of correct free recall was $66.1 \%, 71.4 \%$, and $76.0 \%$ for the $1-, 2-$, and 5 -sec presentation rates, respectively. It should also be noted that the spacing effect was significant, and that it did not interact significantly with presentation rate. However, these effects of spacing cannot be interpreted unambiguously. For college students, the primacy and recency buffers, which were appropriate for preschoolers, were not adequate to avoid contaminating the spacing effect with serial position effects.
2. In the context of his two-process theory, Greene (1989) refers to his account of the spacing effect in free recall as a "study-phase retrieval subtheory. "It is classified here as an encoding-variability theory, because the theory accounts for the superior recall of DP items over MP items by means of an encoding-variability mechanism. That is, DP items are assumed to be recalled better, because they presumably are encoded with a greater variety of contextual elements, thereby increasing the num. ber of possible retrieval cues

(Manuscript received August 9, 1989; revision accepted for publication August 24, 1990.)

\title{
Notice
}

\section{CALL FOR PAPERS}

\author{
Memory \& Cognition Special Issue \\ "Memory and Cognition Applied"
}

\begin{abstract}
Special Issue Editors: Susan Dumais (Bellcore)
Margaret Jean Intons-Peterson (Indiana University)

Associate Editors:

James I. Chumbley (University of Massachusetts)

Robert Proctor (Purdue University)
\end{abstract}

Papers relating to applied memory and cognition are invited for this special issue of Memory \& Cognition to be published in late 1991 or early 1992. The special issue will focus on fruitful interactions between applied and basic research in cognition. Research involving applications of cognitive psychology to real world problems, as well as applied solutions to practical problems, which suggest interesting new research areas are of interest.

We encourage submission of papers on the following topics:

- Cognitive-based design of computer interfaces

- Cognitive problems observed in complex systems

- Educational applications of memory and cognition

- Complex decision making

- Computer or related aids to memory, problem solving, and decision making

- Medical or legal memory and reasoning

- Long-term retention of skills and knowledge

- Prospective memory

Please submit papers as soon as possible. Manuscripts should be submitted to Susan Dumais, c/o Memory \& Cognition, Department of Psychology, Indiana University, Bloomington, Indiana 47405 before April 15, 1991, to be considered for the special issue. Manuscripts will undergo the normal reviewing process and may be published in a regular issue of Memory \& Cognition if appropriate.

For more information, contact:

Susan Dumais

(201) 829-4253

e-mail: STD@BELLCORE.COM
OR Margaret Jean Intons-Peterson

(812) 855-3991

e-mail: INTONS@IUBACS 